\title{
Evaluating Usability of Web-Based Electronic Government: Users' Perspective
}

\author{
Zhao Huang and Laurence Brooks \\ School of Information System, Computing and Mathematics, Brunel University, Uxbridge, \\ Middlesex UB8 3PH, UK \\ \{zhao.huang, Laurence.brooks\} @brunel.ac.uk
}

\begin{abstract}
Electronic government (e-government) has been rapidly developed to increase services delivery and users' access to government information. Users' interaction with e-government is largely dependent upon how easy to use egovernment websites. In this aspect, usability needs to be importantly addressed when developing e-government. As such, an empirical study is conducted to evaluate usability of current e-government websites focusing on users' perception and performance. The results indicate that a number of usability problems have been found in the target e-government websites. Furthermore, performance results show the different levels of users' interaction with the egovernment websites evaluated. More significantly, a close relationship between users' perception of usability and their performance is indicated. These findings can help designers identify users' usability requirements and draw their particular attention to further develop more usable e-government websites.
\end{abstract}

Keywords: Web-based e-government, Usability, Users' perception, Users' performance.

\section{Introduction}

Traditional government is a complex and mammoth bureaucracy, which makes access to information difficult and provision of government services frustrating for users [1]. Users want to establish a new approach for better government, which enables easier access, richer information resources, higher quality services and more enjoyable participation [2]. Furthermore, government is required to change the way of administering and processing official business [3], delivering government services and generating greater efficiency for all participation [4]. In response to these requirements, e-government becomes an outstanding solution [5].

Today, governments worldwide have rapidly developed their web-based egovernment systems. Among the 192 member countries of the United Nations, nearly $98 \%$ of countries have built web-based e-government systems [6]. However, the average e-government website usage by users is low, about 30\% [4]. Among the reasons for this, usability has been found to be a major factor influencing users' engagement with e-government websites. A higher level of usability can lead to better systems quality and help users more easily and effectively accomplish what they want 
to do on the e-government websites. As such, usability of e-government websites needs to be considered when developing e-government websites.

However, current research has not paid enough attention to evaluating usability of e-government websites. Without addressing usability at the detailed level in egovernment websites design, e-government will not be fully used by the wider range of users. Since e-government is used by diverse users who have heterogeneous backgrounds, there are a range of requirements for usability from e-government. Such different requirements make usability identification difficult for designers trying to develop more usable e-government. To this end, an empirical study is conducted to evaluate the usability of current e-government websites. By doing so, it can provide insight into e-government usability. In addition, this study addresses the users' perspective, which increases understanding of users and their usability needs. This offers concrete prescriptions for developing more user-centered e-government websites that can support users achieving the desired services outcomes and so generate greater participation. To implement the evaluation, the heuristic evaluation method is considered as appropriate, with its usefulness and applicability already proven in many studies [7]. In detail, the heuristic evaluation is based on users' perception of Nielsen's set of usability heuristics. Furthermore, in order to obtain comprehensive evaluation, users' performance is also measured showing the level of users' interaction with the e-government websites when they perform specific tasks.

The paper is structured as follows: section 2 reviews relevant studies to indicate the importance of usability to e-government websites. This is followed by designing an empirical study to evaluate usability (section 3). Section 4 discusses the evaluation results. Finally, the conclusion and future research are suggested in section 5.

\section{Relevant Studies}

\subsection{E-Government Websites}

Since all e-government information and services are delivered through e-government websites, these websites can therefore be seen as the interface of the e-government, serving as a window for users to communicate with governments [8]. Alongside egovernment development, e-government website functionality has significantly evolved. Initially, the website is simply used to publish information. However, the website matures quickly and functionality is increased by adding search facility, personalized web content and online transaction [9]. Recently, website functionality is underlying systems integration [8]. With high levels of integration, users can simply follow a single registration process to become involved in multiple online government services [10]. An e-government website has the potential to change the way that users access and interact with government. As such, e-government websites are a key priority when governments develop their e-government systems and create electronic relationships [11]. In the UK, $30 \%$ of e-government projects are focused on website development [12]. However, the target of great users' interaction with e-government remains a challenge. Evidence indicates that usability is a vital factor in deciding users' participation. 


\subsection{Usability}

Usability can be seen as a measurement related to how useful and user-friendly the system is. In detail, usefulness is the degree to which users think that using the particular system can improve their performance [4], while user-friendliness is the perception of aesthetic design regarding interface features [13]. Usability is an important factor in system quality. While a successful and preferred website generally refers to one with high usability, equally, usability can significantly influence users' preferences, opinions and attitudes [14]. Furthermore, usability has big impacts on user performance with systems. A study investigating users' expectations about egovernment shows that users' preferences closely relate to usability in terms of the degree of access of e-government services, findability of the e-government website, loading speed of the pages, the usefulness of information provided on the site and flexibility that is being offered through the e-government website [15]. A high level of usability enhances users' expectations, which has a decisive effect on their use of e-government. Thus, there is a need to evaluate usability of e-government websites to improve its usage.

\section{Methodology}

An experimental study is carried out to evaluate the usability of current e-government websites. There are three research instruments: the selected e-government websites, the task sheet and the usability questionnaire. The e-government website is selected as representative of e-government. The task sheet contains a set of tasks that is developed for the participants to perform. The usability questionnaire is designed to identify the participants' perception of usability.

\subsection{E-Government Websites Selection}

The local level of e-government website is selected in this study, because a) it is the closest level for users; b) it is frequently used by the public since the local level is more informational for users and focuses on the needs of users in accessing information and services [16]; c) it can show the effects of e-government on users [17] and d) evidence from studies finds that bigger challenges exist at the local level of e-governments and in their website design. Therefore, the study uses three local egovernment websites in the U.K: called London Authority 1, 2 and 3.

\subsection{Task Sheet}

The participants are required to perform a set of practical tasks on the target egovernment websites. Such tasks are representative activities that users would be expected to carry out on an e-government website. The task sheet is used to detail these tasks for the participants for the usability evaluation. Generally, there are three categories of e-government services [11]: information dissemination, products and services offered and user participation. Information dissemination is related to the provision of all types of government information. Products and services offered refers to delivering one-way services, such as document downloads. User participation 
involves users interacting with two-way services, for example, tax payment. Based on these service categories, a set of relevant task were designed.

\subsection{Usability Questionnaire}

A questionnaire is used to identify users' perception of usability of the target egovernment websites. The design of this questionnaire is based on Nielsen's usability heuristics [18]. There are three steps in the questionnaire design. First, extend the existing usability heuristics to fit the specific needs of e-government. Second, a set of associated criteria for each heuristic are developed in order to focus on the detailed aspects of usability. Finally, the specific questions are developed, based on these heuristic criteria.

Extension of usability heuristics. Nielsen's usability heuristics (Tables 1) have been widely used for usability inspection and its applicability and validation have been proved in many studies [7]. In particular, these heuristics can effectively discover usability issues in relation to website design [19]. As such, this study uses these heuristics as a starting point to evaluate the e-government websites usability.

Table 1.Nielsen's usability heuristics [18]

\begin{tabular}{|l|l|}
\hline Usability Heuristics & Explanations \\
\hline 1. Visibility of system & The site should keep users informed about system status. \\
2. Match real world & The site should use the user' language, real-world conventions. \\
3. User control & The site should make undo and redo functions available. \\
4. Consistency & The site should keep the same design features through the site. \\
5. Error prevention & The site should support users to overcome errors. \\
6. Recognition rather & The site should make objects easy to remember. In addition, \\
than recall & instruments on the site should be visible and easily retrievable. \\
7. Efficiency of use & The site should consider usage for novice, experienced users. \\
8. Aesthetic design & Dialogues should not contain irrelevant information. \\
9. Recover errors & The site should indicate the problem and suggest a solution. \\
10. Help and & The site should provide help and documentation that can be \\
documentation & easy to search, focus on the users' tasks, list concrete steps. \\
\hline
\end{tabular}

However, these heuristics were developed many years ago and use for general website evaluation purposes. To meet the needs of e-government websites, it is necessary to extend Nielsen's heuristics. Relevant studies indicate that e-government is used by a wide range of people, while interoperability is important in terms of information and service exchange [11]. In addition, since e-government is used by diverse users who have heterogeneous skills, therefore, e-government should support these users to complete services. Furthermore, during users' interaction, egovernment should respect their users at all times [20]. Therefore, the existing Nielsen's heuristics are extended by adding three further heuristics: 'Interoperability', 'Support users' skills' and 'Pleasurable and respectful interaction' (Table 2). 
Table 2. Extended usability heuristics

\begin{tabular}{|l|l|}
\hline Extended Heuristics & Explanations \\
\hline 11. Interoperability & $\begin{array}{l}\text { The site should make all service parts, design elements, the site } \\
\text { functions work as a whole to support user task completion. }\end{array}$ \\
12. Support users' skills & $\begin{array}{l}\text { The site should support, extend users' current skills. } \\
\text { The site should present a pleasant design, treat with respect. }\end{array}$ \\
\hline
\end{tabular}

Associated criteria development. Although Nielsen's usability heuristics are extended, these heuristics are still too general to develop the usability questionnaire. It may result in a usability evaluation without enough depth. Furthermore, the lack of detailed analysis may lead to failure in specific usability problem detection. Accordingly, it is important to develop a set of associated criteria. Such criteria are developed from relevant usability studies and the interpretation of wider egovernment studies. The findings of these studies are used to identify which website design features may influence users' perception of usability or cause problems when users interact with systems. These features are extracted to develop the criteria and then grouped into corresponding heuristics.

Usability questionnaire design. Based on the associated criteria, a questionnaire is created for the purpose of capturing the participants' assessment of usability of the target e-government websites. The participants are required to respond using a fivepoint Likert scale, which can indicate the participants' agreement level to the statements.

\subsection{Evaluation Procedure}

To conduct the evaluation, 36 participants were assigned to evaluate three target egovernment websites. Each target e-government website evaluation involved 12 participants. Each participant follows the same evaluation process, which are: free review, task implementation and completing the questionnaire. Free review allows the participants to look through the target e-government website several times. They can freely either look at the overall e-government website or focus on the specific website design elements. Subsequently, the participants are required to complete a set of tasks on the e-government website. Having accomplished all the tasks, the participants are finally asked to fill in the usability questionnaire.

\subsection{Data Analysis}

The data analysis techniques used are the one-way ANOVA and the one-sample Ttest. Statistical analysis is conducted using SPSS for windows (version 13). The significant value $(\mathrm{P})$ is pre-defined as less than 0.05 . In detail, to indicate whether the three London Authorities have a difference in the participants' overall perception of usability, a one-way ANOVA is conducted with three London Authorities as independent variables and usability perception as the dependent variable. Similarly, the one-way ANOVA is employed to indicate whether the three London Authorities show differences in users' performance. In addition, to indicate whether there is a difference between the perception of overall usability and the perception of specific usability features in each target London Authority, a one-sample T-test is conducted. 


\section{Discussion of the Results}

\subsection{Users' Perception}

In general, the results indicate that usability has been considered in the three egovernment websites as a number of usability strengths have been detected (Table 3 ).

However, a number of usability problems have also been identified in each target e-government website (see Table 4). Among these problems, a lower mean score indicates a more serious problem. In London Authority 1, the most serious usability problem is that users are confused by links that have many different colors. Link color is used to indicate different resources within the site. An appropriate number of link colors can visually support users to distinguish between resource differences, so that target information can be easily located to meet users' needs. Using this, users with limited color vision can quickly recognize the difference among subjects [21]. On the contrary, links with many different colors may visually influence the site's appearance and obstruct users' color vision, which may result in difficulty and confusion in information identification in London Authority 1.

In London Authority 2, the most serious problem found is that the options on the home page are not clearly enough presented. Users' subject recognition would be better supported by having clearly presented more understandable options. It can simplify the content presentation and improve its readability. As such, it can help users to quickly understand the subject presented on pages and easily select the relevant options to obtain their expected information. However, options without clear presentation can lead to page content complexity. A starting page with high complexity makes user less pleasurable and users perform worse on search and recognition subjects on such pages [22]. Therefore, the problem of the subject options not being clearly presented on the home page of London Authority 2 affects subject content presentation, which may cause users difficulty with information seeking.

Regarding London Authority 3, the most serious usability problem is that subject categories are presented without a logical order. A logical order of subjects is used to indicate a sequence of information organization, which supports users having a sensible way to scan subject information. It assists users' understanding of the overall subject arrangement and reduces memory load problems. When topics are arranged with a particular order, users are able to easily locate items; remember items of interest viewed previously and access primary information quickly [23]. Conversely, when subject categories are presented without a logical order, users may feel it difficult to scan and find subjects among the categories on the site.

Table 5 presents the overall usability evaluation of the three e-government websites. The results indicate that London Authority 2 has the worst usability assessment, London Authority 1 is next, while the e-government website with best overall usability assessment is shown to be London Authority 3 .

\subsection{Users' Performance}

Table 6 presents the participants' performance with the three London Authorities. Users' performance is measured by a number of performance criteria through 
Table 3. Usability strengths in London Authorities 1, 2 and 3

\begin{tabular}{|c|c|}
\hline London Authority 1 usability strengths & Mean (SD) \\
\hline Users can easily move forward and backward within the site. & $4.33(0.49)$ \\
\hline Significance & $\mathrm{T}=6.215, \mathrm{P}=0.000$ \\
\hline $\begin{array}{l}\text { Site offers "A-Z" service that supports users to quick find the } \\
\text { relevant information for the specific tasks. }\end{array}$ & $4.08(0.79)$ \\
\hline Significance & $\mathrm{T}=2.767, \mathrm{P}=0.018$ \\
\hline Different displays on each page are compatible through the site & $3.92(0.52)$ \\
\hline Significance & $\mathrm{T}=3.139, \mathrm{P}=0.009$ \\
\hline London Authority 2 usability strengths & Mean $(\mathrm{SD})$ \\
\hline The options/links used are all working properly. & $4.25(0.452)$ \\
\hline Significance & $\mathrm{T}=7.123, \mathrm{P}=0.000$ \\
\hline Each image corresponds to each context. & $4.17(0.577)$ \\
\hline Significance & $\mathrm{T}=5.080, \mathrm{P}=0.000$ \\
\hline Users can easily move forward and backward within the site. & $4.00(0.853)$ \\
\hline Significance & $\mathrm{T}=2.762, \mathrm{P}=0.018$ \\
\hline A title with every page clearly indicates the subject of the content. & $3.92(0.793)$ \\
\hline Significance & $\mathrm{T}=2.607, \mathrm{P}=0.024$ \\
\hline The site's functionality supports users to complete most tasks. & $3.75(0.452)$ \\
\hline Significance & $\mathrm{T}=3.294, \mathrm{P}=0.007$ \\
\hline London Authority 3 usability strengths & Mean (SD ) \\
\hline Each page is always followed the same display format. & $4.67(0.492)$ \\
\hline Significance & $\mathrm{T}=5.816, \mathrm{P}=0.000$ \\
\hline The site' functionality supports users to complete most tasks. & $4.67(0.492)$ \\
\hline Significance & $\mathrm{T}=5.816, \mathrm{P}=0.000$ \\
\hline A title on every page clearly indicates the subject of the content. & $4.58(0.669)$ \\
\hline Significance & $\mathrm{T}=3.852, \mathrm{P}=0.003$ \\
\hline Key information/subject is placed in a central location on the page. & $4.50(0.674)$ \\
\hline Significance & $\mathrm{T}=3.391, \mathrm{P}=0.006$ \\
\hline It is easy to operate the e-government website. & $4.42(0.669)$ \\
\hline Significance & $\mathrm{T}=2.988, \mathrm{P}=0.012$ \\
\hline $\begin{array}{l}\text { It is quick to change the particular data in a previous section so users } \\
\text { do not need to retype all the data when they go back. }\end{array}$ & $4.42(0.793)$ \\
\hline Significance & $\mathrm{T}=2.519, \mathrm{P}=0.029$ \\
\hline Users can move forward and backward within the site. & $4.25(0.622)$ \\
\hline Significance & $\mathrm{T}=2.285, \mathrm{P}=0.043$ \\
\hline
\end{tabular}

$(\mathrm{SD}=$ Std. Deviation)

observation. These criteria include amount of online help required, time spent completing all tasks; number of steps to finish tasks and number of successful tasks completed. The results show that the participants in London Authority 2 required more online help and took more steps to accomplish tasks than those in London Authorities 1 and 3. Furthermore, regarding the number of successful tasks completion, the participants in London Authority 2 finished fewer tasks than the participants in London Authorities 1 and 3. These are reflected in the findings of the overall users' perception of usability, which shows that London Authority 2 has the worst overall usability of the three target e-government websites. This implies that the overall users' perception of usability positively influence users' performance. 
Table 4. Usability problems in London Authorities 1, 2 and 3

\begin{tabular}{|l|r|}
\hline London Authority 1 usability problems & Mean (SD) \\
\hline Users are confused by links that have many different colors. & $2.32(1.084)$ \\
\hline Significance & $\mathrm{T}=-3.303, \mathrm{P}=0.007$ \\
\hline Online help function is not clearly indicated on the website. & $2.33(1.155)$ \\
\hline Significance & $\mathrm{T}=-3.350, \mathrm{P}=0.006$ \\
\hline It is difficult to switch between online help and current work. & $2.75(0.866)$ \\
\hline Significance & $\mathrm{T}=-2.800, \mathrm{P}=0.017$ \\
\hline London Authority 2 usability problems & Mean (SD) \\
\hline Some options on the home page are not clearly presented. & $2.17(1.030)$ \\
\hline Significance & $\mathrm{T}=-3.879, \mathrm{P}=0.003$ \\
\hline Users are confused by links that have many different colors. & $2.25(0.866)$ \\
\hline Significance & $\mathrm{T}=-4.280, \mathrm{P}=0.001$ \\
\hline The site sometimes does not indicate a task's progress. & $2.33(0.888)$ \\
\hline Significance & $\mathrm{T}=-3.851, \mathrm{P}=0.003$ \\
\hline Links already visited are not clearly marked. & $2.50(1.243)$ \\
\hline Significance & $\mathrm{T}=-2.285, \mathrm{P}=0.043$ \\
\hline The site allows users to skip over the order of the process. & $2.67(0.778)$ \\
\hline Significance & $\mathrm{T}=-2.907, \mathrm{P}=0.014$ \\
\hline London Authority 3 usability problems & $\mathrm{Mean}(\mathrm{SD})$ \\
\hline Subject categories are presented without a logical order. & $2.83(1.030)$ \\
\hline Significance & $\mathrm{T}=-3.386, \mathrm{P}=0.006$ \\
\hline Users are confused by links that have many different colors. & $2.58(0.669)$ \\
\hline Significance & $\mathrm{T}=-6.511, \mathrm{P}=0.000$ \\
\hline Links already visited are not clearly marked. & $2.92(1.084)$ \\
\hline Significance & $\mathrm{T}=-2.952, \mathrm{P}=0.013$ \\
\hline Information is unbalanced between breadth and depth. & $3.00(0.853)$ \\
\hline Significance & $\mathrm{T}=-3.412, \mathrm{P}=0.006$ \\
\hline SD Std. Devation)
\end{tabular}

$(\mathrm{SD}=$ Std. Deviation $)$

Table 5. Overall usability assessment in the target London Authorities

\begin{tabular}{|lcccccc|}
\hline & \multicolumn{2}{c}{ London Authority 1 } & \multicolumn{2}{c|}{ London Authority 2} & \multicolumn{2}{c|}{ London Authority 3} \\
\hline & Mean & SD & Mean & SD & Mean & SD \\
\hline Overall usability & 3.445 & 0.304 & 3.323 & 0.367 & 3.843 & 0.275 \\
\hline Significance & & & & & $\mathrm{F}=8.784, \mathrm{p}=0.001$ \\
\hline
\end{tabular}

$(\mathrm{SD}=$ Std. Deviation)

However, regarding performance in terms of time spent for all tasks completion, the results indicate that the participants who are in London Authority 1 spent more time to finish all tasks than those who are in London Authorities 2 and 3. Such results are not echoed in the findings of the overall users' perception of usability, in which London Authority 1 has not the worst overall usability among the target e-government websites. Based on the results, a possible explanation is that the participants' performance may be not only affected by the overall perception of usability, but also affected by the particular perception of usability. As the most serious usability problem identified in London Authority is that users are confused by links having 
many different colors. This problem closely relates to the heuristic "aesthetic design" (Table 1). Evidence from relevant studies indicates that system aesthetics can be seen as apparent usability, which is perceived more quickly than other attributes of usability [24]. Therefore, users' perception of website aesthetic design may also influences users' performance, especially in London Authority 1.

Table 6. Users' performance in London Authorities 1, 2 and 3

\begin{tabular}{|lcccccc|}
\hline & London Authority 1 & \multicolumn{2}{c}{ London Authority 2 } & \multicolumn{2}{c|}{ London Authority 3 } \\
\hline & Mean & SD & Mean & SD & Mean & SD \\
\hline Online help required & 0.250 & 0.452 & 0.583 & 0.669 & 0.000 & 0.000 \\
\hline Significance & & & & & $\mathrm{F}=4.733, \mathrm{P}=0.016$ \\
\hline Number of steps & 60.417 & 13.104 & 81.833 & 20.687 & 50.167 & 16.297 \\
\hline Significance & & & & & $\mathrm{F}=10.862, \mathrm{P}=0.000$ \\
\hline Tasks completion & 1.139 & 0.117 & 1.148 & 0.086 & 1.065 & 0.088 \\
\hline Significance & & & & & $\mathrm{F}=2.590, \mathrm{P}=0.090$ \\
\hline Time spent & 26.627 & 8.905 & 21.721 & 8.579 & \multicolumn{1}{c|}{16.209} & 8.102 \\
\hline Significance & & & & & $\mathrm{F}=4.474, \mathrm{P}=0.019$ \\
\hline
\end{tabular}

$(\mathrm{SD}=$ Std. Deviation $)$

\section{Conclusions}

This study has evaluated usability of current e-government websites in the UK. A number of usability problems have been found in the target e-governments. This suggests that current e-governments need to improve their usability. In addition, it appears that usability issues have not been considered at a detailed level in egovernment websites design, which influences users' task performance. These results can help designers understand e-government websites usability, especially identifying users' usability requirements. Furthermore, these identified usability problems can draw designers' particular attention to their websites and support them to further improve usability. Additionally, the common usability problems detected can be used as reference to check usability for other e-government websites. However, this study has some limitations. For example, regarding usability criteria development, some criteria might be found to relate to more than one heuristic; however, the study grouped these criteria into one heuristic based on their key features. Moreover, to fulfill a thorough usability study, there is a need to offer concrete prescription for the identified usability problems in order to improve usability of the target e-government websites. Future research will propose the design solutions and examine the effects of the proposed design solutions on the usability problems identified in this study.

\section{References}

1 Cairns, G., Wright, G., Bradfield, R., Heijden, K., Burt, G.: Exploring e-government futures through the application of scenario planning. Technological Forecasting and Social Change 71(3), 217-238 (2004) 
2 OECD: OECD E-Government Studies: the e-government imperative, Paris (2003)

3 Yang, L., Lu, Y., Fu, G.: Study on e-government construction. In: Proceeding of the 4th International Conference on Entertainment Computing, pp. 542-548 (2005)

4 Kumar, V., Mukerji, B., Butt, I., Persaud, A.: Factors for successful e-government adoption: a conceptual framework. Electronic Journal of E-government 5(1), 63-76 (2007)

5 Kelly, E.P., Tastle, W.J.: E-government and the judicial system: online access to case information. International Journal of Electronic Government 1(2), 166-178 (2004)

6 UN Public Administration Programme 2010: United Nations e-government survey (2010), http: / / www2 . unpan.org/egovkb/global_reports/10report.htm

7 Hvannberg, E.T., Law, E.L., Larusdottir, M.K.: Heuristic evaluation: comparing ways of finding and reporting usability problems. Interacting with Computers 19, 225-240 (2007)

8 Gant, J.P., Gant, D.B.: Web portal functionality and state government e-services. In: The 35th Hawaii International Conference on System Science, pp. 1627-1636 (2002)

9 Kossak, F., Essmayr, W., Winiwarter, W.: Applicability of HCI research to e-government. In: 9th European Conference on Information Systems, pp. 957-968 (2001)

10 Dwivedi, Y.K., Williams, M.D.: Demographic influence on UK citizens' e-government adoption. International Journal of Electronic Government 5(3), 261-274 (2008)

11 Garcia, A.C.B., Maciel, C., Pinto, F.B.: A quality inspection method to evaluate Egovernment sites. In: Wimmer, M.A., Traunmüller, R., Grönlund, Å., Andersen, K.V. (eds.) EGOV 2005. LNCS, vol. 3591, pp. 198-209. Springer, Heidelberg (2005)

12 Beynon-Davies, P., Williams, M.D.: Evaluating electronic local government in the UK. Journal of Information Technology 18(2), 137-149 (2003)

13 Matera, M., Costabile, M.F., Garzotto, F., Paolini, P.: SUE inspection: an effective method for systematic usability evaluation of hypermedia. IEEE Transaction on System, Man, and Cybernetics - Part A: Systems and Human 32(1), 93-103 (2002)

14 Lee, S., Koubek, R. J.: The effects of usability and web design attributes on user preference for e-commerce web sites. Computers in Industry (2010); doi:10.1016/ j.compind.2009.12.004

15 Verdegem, P., Verleye, G.: User-centered e-government in practice: a comprehensive model for measuring user satisfaction. Government Information Quarterly 26, 487-497 (2009)

16 Reddick, C.G.: The adoption of centralized customer service systems: a survey of local governments. Government Information Quarterly 26(1), 219-226 (2009)

17 Tolbert, C., Mossberger, K.: The effects of e-government on trust and confidence in government. In: Proceedings of the 2003 Annual National Conference on Digital Government Research, Digital Government Research Center, pp. 1-7 (2003)

18 Nielsen, J.: Heuristic evaluation: usability inspection methods, New York (1994)

19 Nielsen, J.: Deigning web usability: the practice of simplicity, Indiana, USA (2000)

20 Reddick, C.G.: Citizen interaction with e-government: from the streets to servers? Government Information Quarterly 22(1), 38-57 (2005)

21 Kappel, G., Pröll, B., Reich, S., Retschitzegger, W.: Web engineering, the discipline of systematic development of web applications. John Wiley \& Sons, Chichester (2006)

22 Tuch, A.N., Bargas-Avila, J.A., Opwis, K., Wilhelm, F.H.: Visual complexity of websites: effects on users' experience, physiology, performance, and memory. International Journal of Human-Computer Studies 67(9), 703-715 (2009)

23 Brinck, T., Gergle, D., Wood, S.D.: Usability for the web: designing web site that work. Morgan Kaufmann Publishers, San Francisco (2002)

24 Tractinsky, N.: Aesthetics and apparent usability: empirically assessing cultural and methodological issues. In: Proceedings of ACM Conference on Human Factors in Computing Systems, pp. 115-122. ACM Press, New York (1997) 